\title{
Going Home: Evacuation-Migration Decisions of Hurricane Katrina Survivors
}

\author{
Craig E. Landry, Okmyung Bin, Paul Hindsley, John C. Whitehead, and Kenneth \\ Wilson ${ }^{*}$
}

April 11, 2007

\footnotetext{
* The authors are respectively, Assistant Professor of Economics and Assistant Director of Center for Natural Hazards Research, East Carolina University; Associate Professor of Economics, East Carolina University; Doctoral Candidate in Coastal Resources Management, East Carolina University; Professor of Economics, Appalachian State University; and Associate Professor of Sociology, East Carolina University. This research was funded by National Science Foundation grants: 1) (CMS 0553108) "SGER:

Collecting Economic Impact Data: Implications for Disaster Areas and Host Regions," 2) (SES 0554987) "SGER: The "New" New Orleans: Evaluating Preferences for Rebuilding Plans after Hurricane Katrina," and 3) (SES 0552439) "SGER: Cooperation among evacuees in the aftermath of Hurricane Katrina." The NSF bears no responsibility for the comments or conclusions reached within this study. Our sincere gratitude goes to Jamie Kruse for providing the economic impact data and Rick Wilson for providing the Houston evacuee data.
} 


\section{Going Home: Evacuation-Migration Decisions of Hurricane Katrina Survivors}

In the wake of Hurricane Katrina, many evacuees from the Gulf region began the difficult process of deciding whether to rebuild or restart elsewhere. We examine preKatrina Gulf residents' decision to return to the post-disaster Gulf region-which we call the "return migration" decision. We estimate two separate return migration models, first utilizing data from a mail survey of individuals in the affected region and then focusing on self-administered questionnaires of evacuees in Houston. Our results indicate that return migration can be affected by household income; age; education level; employment, marital and home ownership status; but the results depend upon the population under consideration. We find no impact of "connection to place" on the return migration decision. While the impact of income is relatively small, we find that the real wage differential between home and host region influences the likelihood of return. Larger implicit costs, in terms of foregone wages for returning, induce a lower likelihood of return. Exploiting this difference at the individual level, we are able to produce estimates of willingness to pay to return home. Average WTP to return home for a sample of relatively poor households is estimated at $\$ 1.94$ per hour or $\$ 3,954$ per year.

\section{JEL classifications: I3, J6, Q54, R23}




\section{Introduction}

Upwards of one million residents of the greater metropolitan New Orleans area evacuated on the $27^{\text {th }}$ and $28^{\text {th }}$ of August 2005, just before Hurricane Katrina struck the Gulf Coast. Evacuees from other parts of Louisiana, Mississippi, and Alabama fled the coast in large numbers, marking Hurricane Katrina as the largest population displacement in the United States since the Dust Bowl of the 1930s (Falk, Hunt, and Hunt 2006). Postdisaster recovery and rebuilding in the Gulf region requires understanding the existing risks, communicating those risks to the public, rethinking land uses, deciding on methods to correct deficiencies in public infrastructure, and providing incentives for economic recovery that will give firms and households an opportunity to survive and thrive. In the case of New Orleans, recovery may take up to 11 years or more (Kates et al. 2006). While many issues remain to be resolved in determining what will become of New Orleans and the Gulf region, the economic, social, and cultural future of the Gulf region will be significantly influenced by who decides to return. In the face of variable but widespread destruction, salient vulnerability, and uncertain prospects, evacuees must choose whether to return to their home.

As Katrina approached, Alabama, Mississippi, and Louisiana all issued mandatory evacuation orders. In New Orleans, 70,000 people remained, some by choice, but most without means of escape (U.S. Congress CGR 2006). Many evacuees who sought refuge from Katrina had nowhere to return to after the storm. Immediately after the storm, roughly 275,000 people were forced into group shelters (FEMA 2006a). Between mid August and mid November of 2005, 250,000 people lost their jobs (U.S. 
Congress CBO 2006). Without homes or jobs, many people were forced to decide whether to restock and rebuild their lives along the Gulf coast or to seek out a new location for residence. The National Hurricane Service estimated the total damage losses from Katrina at $\$ 81.2$ billion (NWS 2006). In the 117 hurricane-affected counties of the Gulf Coast, 40 declined in population between July 1, 2005 and January 1, 2006 (Frey and Singer 2006). The greatest population losses occurred in the parishes and counties holding New Orleans, LA; Gulfport-Biloxi, MS; Lake Charles, LA; Pascagoula, MS; and Mobile, AL.

In this paper, we examine the decision to return to the post-disaster Gulf regionwhich we call the "return migration" decision. We review economic models of household migration and build upon historical and empirical evidence of migration behavior in order to postulate on determinants of post-disaster return migration. We identify important research questions that can be examined with return migration data. We explore stated preference return migration behavior using a number of datasets collected in the wake of Hurricane Katrina and make some inferences about socioeconomic determinants and impacts of the return migration decision.

\section{Economic Models of Household Migration}

Economists have long recognized that economic factors influence the migration patterns of households. Sjaastad (1962) provides a theoretical framework for the decision to migrate, defining the problem in terms of a household's search to maximize the net economic return on human capital. In this framework, migration is viewed as an equilibrating force in the labor market—real wage differences between regions or cities 
create arbitrage opportunities that can be realized by migration, leading to a redistribution of households across the landscape. Early models focused on interspatial wage differentials, distance between origin and destination, labor market conditions-such as unemployment rate and growth in employment — and household characteristics as factors determining migration flows (Greenwood 1975; Graves 1979, 1980; Greenwood and Hunt 1989).

Models of household migration typically employ a modified gravity modeling structure. Migration flows are assumed proportional to origin and destination populations, but inversely related to distance. It has been well documented that migration rates decline with distance, though it is generally believed that out-of-pocket monetary expenses could not alone explain this phenomenon. Moving expenses tend to be a relatively small part of the net returns to migrating. Other explanations include opportunity costs of time, psychic costs of moving (diminution of contact with family and friends, change of environment, etc.), higher search costs associated with greater distances, and uncertainty about destinations (Greenwood 1997). The existence of these potential barriers to migration has created concern about the efficacy of migration in reallocating resources in response to changing market and demographic conditions.

Migration decisions vary across individual households. Economic factors such as worker skills and employment status will influence returns to migration. Life-cycle considerations and the availability of information may also influence migration. One would expect some correspondence between migration and changes in life stages-for example, children moving away from home, the completion of school by a family 
member, marriage, divorce, retirement, etc. Expectations of obtaining gainful employment depend upon flow of information on employment opportunities, which may explain why previous-period net migration rates are positively correlated with current migration trends (Greenwood 1969). Social networks may play a role in learning about labor market opportunities and providing support for migration. Especially among raceethnic minority groups, research suggests that migration patterns tend to follow wellworn pathways and networks (Bean and Tienda 1987; Farley and Allen 1987; Barringer, Gardner, and Levin 1993).

Individuals might also be influenced through learning about amenities in different locations. Sjaastad (1962) considered location-specific amenities (including climate, smog, and congestion) as factors that might affect returns to migration, but characterized them as unimportant in evaluating migration as a redistributive mechanism since they entail no resource cost. This notion does suggest, however, that location-specific amenities may affect the reservation wage of households, and thus that wage schedules could be conditional on amenity levels. A subsequent branch of literature adopted this perspective, assuming wages, rents, and the prices of locally produced non-traded goods adjust in response to location-specific exogenous factors, such as local environmental conditions or fiscal considerations, so that utility and profit levels (rather than wages and land rents) are equalized across regions. Under this characterization, persistent differences in wages and rents compensate for amenity levels; they need not equalize across regions or cities in the long run unless the locations have identical amenities. 
Roback (1982) shows how wages and land rents are simultaneously determined in an equilibrium setting, conditional on the level of local amenities. In this context, amenities are non-manufactured attributes that are valued by households-such as temperature, rainfall, and cleanliness of environment—or goods and services that vary in availability spatially—such as professional sports teams, performing arts, cultural resources (i.e. museums), etc. In Roback's model, interregional wages and rent differentials can persist and will reflect the value of location-specific amenities. This formulation of household migration follows the hedonic model formalized by Rosen (1974) in the sense that implicit values of location-specific amenities are reflected in the markets for labor, land, and other locally produced goods and services.

Clark and Cosgrove (1991) examine the persistency of interregional wage differentials. They find evidence that supports both the human capital approach of Sjaastad and the compensating differentials model of Roback. Amenities tend to have a significant negative effect on wages, but wage differentials persist across regions even when amenities are controlled. Greenwood et al. (1991) provide evidence of disequilibrium in U.S. internal migration between states-real income in amenity rich states tends to be too high and real income in amenity poor areas tends to be too low.

Frey and Liaw (2005) identify cultural constraints—-such as need for social support networks, kinship ties, and access to informal employment opportunities-as shaping the migration patterns of race-ethnicity groups. Empirical evidence suggests that minority residence in an ethnically concentrated metropolitan area can inhibit outmigration (Tienda and Wilson 1992). Thus, persistent differentials may reflect cultural 
constraints in a number of ways: race-ethnic groups may traverse well-worn migration routes with less attention paid to wage differentials at other possible destinations; or connections to place ${ }^{1}$ may inhibit out-migration. The implications of this line of reasoning are that migration may not engender complete efficiency in the allocation of labor across space, as social and personal constraints may inhibit labor flow. Greenwood et al. (1991) suggest that persistent wage differentials are relatively small, so that efficiency loss could be minor. However, exploration and inference about social connections is something that, to our knowledge, has not been explored. Such an analysis is best pursued with micro-level data.

\section{Examining Return Migration}

A number of papers have looked at the decision to evacuate prior to hurricane landfall (Baker 1991; Gladwin and Peacock 1997; Dow and Cutter 1997; Whitehead et al. 2000; Whitehead 2005). Results generally suggest that storm intensity, evacuation orders, perception of flood risk, type of residence, pet ownership, and race/ethnicity influence the likelihood of evacuation. Whitehead (2005) finds some evidence to support the validity of stated preference evacuation data.

There has been much less research on post-disaster migration. A disaster large enough to cause widespread displacement of a population will often cause extensive damage to personal property and infrastructure, limiting the ability of evacuees to return to their homes, businesses, and communities. Depending upon the severity of the disaster, return access may be limited for weeks or months. Uncertainty about the timing

\footnotetext{
1 "Place" is defined as a geographical unit in which identity is grounded (Gieryn 2000).
} 
and composition of return migration can hamper the recovery process, as many economic, civic, and social functions are largely population dependent. ${ }^{2}$ The nature of return migration also affects reconstruction, as project prioritization and infrastructure capacity depend upon the returning population.

Elliott and Pais (2006) examine evacuation, short-term recovery, emotional stress and support, and likelihood of return for Gulf coast residents in the wake of Hurricane Katrina. They find a high degree of uncertainty regarding the likelihood of return for those households still displaced one month after the storm. They find homeowners are more likely to return than those that do not own property. However those whose home was destroyed by the storm are less likely to return. They also find that lower-income households are more likely to return. Falk, Hunt, and Hunt (2006) argue that affluent households should be more likely to return post-disaster, as they are likely to be displaced to closer locations and they have better resources to make the return trip. In the case of flooding disasters, affluent households are more likely to own homes in areas less likely to have been flooded, and have better resources to rebuild in the event that their home has been damaged. Note that the results of Elliott and Pais correspond with households that had not returned one month after the disaster. Thus, they are conditioned on their sample selection - those households that did not immediately return. As such, the conjecture of Falk, Hunt, and Hunt may apply to the general population of evacuees.

\footnotetext{
${ }^{2}$ For example, a survey of previous residents one year after a devastating earthquake revealed that $74 \%$ of unskilled workers had not returned to the area, while only $40 \%$ of skilled workers did not return (Bowden et al. 1977).
} 
Elliott and Pias also consider the effect of race, gender, age, timing of evacuation, whether the respondents are parents, and employment status on the likelihood of return. They find no statistical support for the significance of these covariates in the return migration decision. Falk, Hunt, and Hunt (2006) speculate on the importance of sense of place as a factor affecting the likelihood of return. They note that sense of place is likely to increase in strength when families or communities exist in an area for an extended period of time, perhaps over a number of generations. Sense of place may keep households in an area through bad times—-such as loss of job, economic recession, social turmoil, or natural disaster-even when moving elsewhere could afford better opportunity. As such, sense of place might play a role in persistent wage and land rent differentials identified in the economic migration literature. This notion is related to the psychic costs of moving identified by Sjaastad (1962). Sense of place and a desire to rekindle community and social connections could affect the likelihood of return.

Population displacement due to natural disaster offers an opportunity to examine the importance of sense of place in migration decisions. Displacement creates an exogenous shock that uproots households that might have never chosen to leave their current location, despite differences in wages, prices, or amenities in other areas. How do those households then respond given the current opportunities for employment and quality of life in their displaced location and their connection to the place from which they vacated? This choice likely depends upon sense of place and connection to culture. With the right kind of data, one could examine the importance of culture and sense of place in the return migration decision and, by examining contingent wages in the 
displaced and home locations, could possibly get a sense of the compensating real wage differentials that would affect migration despite connection to place.

Post-disaster perceptions may also affect the likelihood of return. Natural disasters can expose shortcomings of certain locations or the way humans have developed the landscape leading to changing perceptions of vulnerability. Those that perceive areas where they previously lived as suddenly more vulnerable would be less likely to return. Likewise, mistrust of government to provide risk management and handle emergency services could also influence return migration to high-hazard areas. Lastly, expectations of housing and job availability as well as overall economic outlook could affect return migration. In the next section, we develop an econometric model of the likelihood of post-disaster return that takes these aspects into account.

\section{Return Migration Decision}

Consider the return migration decision of a household that has recently evacuated prior to a natural disaster. We consider this household displaced if they cannot immediately return to their home after the occurrence of the disaster. Inability to return could reflect damage to their home or community, loss of critical infrastructure (such as roads, power, or flood protection), distance traveled for evacuation, uncertainty related to habitability of their home or continuation of employment, or some combination of these factors. We assume household decision making adheres to the tenets of rational choice, and thus the decision to return post-disaster reflects a weighing of benefits $(B)$ and costs (C). Thus, the probability of return is: 


$$
\operatorname{Pr}(\text { return }=1)=\operatorname{Pr}(B>C),
$$

where return is a dummy variable indicating intention to return; $B$ reflects connection to place, perceptions of vulnerability, damage to home and community, likelihood of reengaging in employment, and the likelihood of friends and family returning; and $C$ reflects distance evacuated and wage differentials in the home and host cities. The $C$ vector might also include differences in prices and amenities in the home and host cities.

Thus, quality of life factors and home-specific factors, such as connections to place and individual perceptions and expectations of future conditions, should play a role in the decision to return. Under the assumption that evacuees can find a job in their host and home cities, a cost of returning home is the change in real wages associated with the return. With persistent interregional wage differentials, the loss in real wages stemming from return migration could be significant. On the other hand, wages in the host region could be less than that of the home region, so the wage differential would be a negative cost. The wage differential will reflect economic conditions in the home and host city and labor characteristics of the household.

The household return migration decision has implications for the economic and social recovery of the region affected by natural disaster. The pool of labor that returns (e.g. skilled vs. unskilled) may affect economic activity and industry performance. While we would expect market adjustments to equilibrate demand and supply of labor over time, shortages or gluts of specific types of labor could cause short term problems in recovery. The availability of housing may exacerbate labor problems - if unskilled labor tends to rent housing and rental properties are neglected in early recovery efforts, then the 
return rate of unskilled labor may be relatively low. This could be a problem for New Orleans, since the tourism-based economy of the city relies heavily on unskilled labor (Falk, Hunt, and Hunt 2006). Demographics of returning households have implications for the public and private sectors of the economies - are families with school-age children likely to return? How should local school districts plan for their return?

The return migration decision can also be explored from the standpoint of nonmarket valuation. Consider the economic value of returning home, maximum willingness to pay (WTP), with $W T P_{i}=x_{i}^{\prime} \beta+\varepsilon_{i}$, where $x_{i}$ is a vector of household characteristics and $\varepsilon_{i}$ is an i.i.d. logistic random error term with zero mean. The conditional probability of return can be rewritten:

$$
\operatorname{Pr}\left(\text { return }=1 \mid x_{i}\right)=\operatorname{Pr}\left(W T P_{i}\left(x_{i}, \varepsilon_{i}\right)>C_{i}\right),{ }^{3}
$$

Consider the real wage differential as the primary cost of return: $C_{i}=w_{\text {host }}-$ $w_{\text {home }}$ Ignoring other potential $\operatorname{costs}^{4}$, we have:

$$
\begin{aligned}
\operatorname{Pr}\left(\text { return }=1 \mid x_{i}\right) & =\operatorname{Pr}\left(x_{i}^{\prime} \beta+\varepsilon_{i}>C_{i}\right) \\
& =\operatorname{Pr}\left(\varepsilon_{i}>C_{i}-x_{i}^{\prime} \beta\right) \\
& =\operatorname{Pr}\left(x_{i}^{\prime} \beta-C_{i}>\varepsilon_{i}\right)
\end{aligned}
$$

\footnotetext{
${ }^{3} \mathrm{Haab}$ and McConnell (2002) illustrate that the willingness to pay function approach is equivalent to a utility difference model (the basis of most discrete choice models) if utility is linear in parameters and the marginal utility of income is constant across the discrete choice states (in our case, going home or remaining in the host city).

${ }^{4}$ Since they are likely to be very small relative to the present value of the wage differential and will only be incurred once, we ignore the pecuniary and time costs of return.
} 


$$
=\operatorname{Pr}\left(\left(x_{i}^{\prime} \beta-C_{i}\right) / \theta>z_{i}\right)
$$

where $z_{i}$ is a standard logistic random variate and $\theta=\sigma^{2} \pi^{2} / 3 .^{5}$ As recognized by Cameron and James (1987), this formulation of dichotomous choice model allows for identification of point estimates of $\beta$ and calculating fitted values of $W T P_{i}$ because the scale parameter is identified due to inclusion of a random cost parameter. The parameter estimate on $C$ from the logistic regression is a point estimate of $-1 / \theta$, so $\beta$ in (3) can be recovered through a simple transformation. In our case, the evacuation location must be exogenously imposed upon the household in order to render $w_{\text {host }}$ a random wage offer, and thus $C_{i}$ exogenous to the household. The expected benefit of return home for the average household is calculated as:

$$
W T P=-\frac{\bar{x}^{\prime} \beta}{\beta_{C}}
$$

where $\bar{x}$ is a vector of average household characteristics and $\beta_{C}$ is the parameter estimate of the wage difference. ${ }^{6}$ Confidence intervals for WTP can be calculated using the Krinsky-Robb Monte Carlo procedure (1986).

\section{Empirical Analysis}

The eye of Hurricane Katrina made landfall in southeast Louisiana at 6:10 a.m. on August 29, 2005. At landfall, Katrina had maximum winds of $125 \mathrm{mph}$, making it the third most intense hurricane on the US record (NWS 2006). Hurricane Katrina

\footnotetext{
${ }^{5}$ Line 3 of Equation (3) only holds for symmetric distribution of $\varepsilon$. The logistic distribution is symmetric.

${ }^{6}$ WTP measure assumes constant marginal utility of income.
} 
devastated the Gulf coast. The National Weather Service (2006) reports that in Mississippi, storm surge reached 28 feet in certain locations. In Louisiana and Alabama storm surge arrived at well above 10 feet. Along the Mississippi coast, storm surge penetrated at least six miles, where preliminary estimates indicated $90 \%$ of structures within a half a mile of the coast were destroyed (CBS 2005; NWS 2006). In New Orleans, levee breaches flooded $80 \%$ of the city. In all, Hurricane Katrina affected roughly 90,000 square miles (FEMA 2006b).

In response to Hurricane Katrina, the Center for Natural Hazards Research at East Carolina University conducted two separate surveys, each containing questions relevant to the evacuation behavior of individuals living within the affected areas. ${ }^{7}$ The two surveys were both random samples of individuals in the affected region, as defined by U.S. Postal Service. ${ }^{8}$ In both cases, we utilized a modified Dillman approach consisting of initial postcards indicating an upcoming survey and multiple waves of mailed surveys and follow-up postcards. We used first-class postage to ensure that the U.S. Postal Service would send our postcards and surveys to the household's forwarding address, and requested return service so that we could keep track of those households which could not be reached via mail. Survey 1, which focused on the expenditure patterns of evacuees, had two waves of mailed surveys and survey 2, which focused on opinions of and preferences for rebuilding projects in New Orleans, consisted of three waves of mailed surveys. Survey 2 also included additional phone contact to encourage participation. In

\footnotetext{
${ }^{7}$ These surveys were the result of two National Science Foundation grants: 1) (CMS 0553108) "SGER: Collecting Economic Impact Data: Implications for Disaster Areas and Host Regions" and 2) (SES 0554987) "SGER: The "New" New Orleans: Evaluating Preferences for Rebuilding Plans after Hurricane Katrina."

${ }^{8}$ These samples were purchased from Survey Sampling of Fairfield, CT.
} 
survey 1, our final targeted sample totaled 2,474 individuals within the affected region. Of these 2,474 individuals, 597 returned surveys - a $24 \%$ response rate. Survey 2 targeted 3,532 individuals of which, 730 were returned surveys- a $21 \%$ response rate. Surveys 1 and 2 were then combined to produce the first set of estimates (Mail Survey in table 2).

The second set of estimates utilizes data collected by researchers at Rice University. ${ }^{9}$ This survey targeted Katrina evacuees in Houston, TX, and consists of three waves of self-administered questionnaires over a one year period. The first wave focused on individuals located in evacuation shelters throughout Houston in early September 2005. The second wave occurred in late October through early November of 2005 in motels and apartment complexes in the city. The third wave occurred in July 2006 in apartment complexes. In all, we utilize 756 observations between the three waves of data. Wilson and Stein (2006) compare descriptive statistics for each wave to other surveys investigating Katrina evacuees in Houston. For a detailed description of the survey methodology, see Wilson and Stein (2006).

We use logistic regressions to analyze evacuees' stated preference decision to return to their pre-disaster residence after Hurricane Katrina. It is assumed that the probability of return depends on a set of individual and household characteristics according to a logistic cumulative distribution function as follows:

\footnotetext{
${ }^{9}$ The Houston evacuee study was sponsored by the National Science Foundation (SES 0552439) "SGER: Cooperation among evacuees in the aftermath of Hurricane Katrina." The grant was awarded to Dr. Rick Wilson, chair of the Department of Political Science and the Herbert S. Autrey Professor of Political Science and Professor of Statistics and Psychology at Rice University.
} 


$$
\operatorname{Pr}(\text { return }=1)=\Lambda\left(x^{\prime} \beta\right)=\frac{\exp \left(x^{\prime} \beta\right)}{\left[1+\exp \left(x^{\prime} \beta\right)\right]}
$$

where $\operatorname{Pr}($ return $=1)$ is the probability that an evacuee returns to the pre-Katrina residence given a vector of individual and household characteristics $x$, and $\Lambda$ represents the logistic cumulative distribution function. The parameters $\beta$ are estimated by method of maximum likelihood.

The vector $x$ varies across our datasets, but in general includes income level of the household, labor characteristics of the household, indicators of cultural and social connection to the previous place of residence, and demographic characteristics. For the entire population of Hurricane Katrina evacuees, we expect that income will have a positive effect on the likelihood of returning, reflecting access to financial resources to aid in return and recovery. Important labor characteristics could include work history and experience, such as whether members of the household are currently employed and whether they were employed before the disaster. Household social and cultural connection indicators could include length of residence at the home location, intergenerational connections to the home area, and membership in a race-ethnic group that has special significance in the home area. Demographic characteristics that might affect the return migration decision include age, education, marital status, and household size. Lastly, the real wage differential $\left(C_{i}\right)$ for the household's skill level and job classification associated with the home and host locations could be included in the specification of (5).

Unlike the linear regression model, the parameter estimates for the logit model are interpreted as the rate of change in the log odds of return as the characteristics change, 
which is not very intuitive. Therefore, the marginal effects of the individual and household characteristics on the probability of return are also calculated, as follows (Greene 2003):

$$
\frac{\partial \operatorname{Pr}}{\partial x_{i}}=\Lambda\left(x_{i}^{\prime} \beta\right)\left[1-\Lambda\left(x_{i}^{\prime} \beta\right)\right] \beta
$$

The marginal effects are evaluated at the observed mean values, which are reported in table 1. For dummy variables marginal effects are computed using the change in the probabilities.

Table 1 reveals striking differences across our two samples. The mail sample corresponds with higher income, more highly educated, and an older population. This population also has less African Americans than the Houston sample. ${ }^{10}$ Almost a third of the mail sample lived in the New Orleans metropolitan area prior to Hurricane Katrina, while the Houston sample is predominantly composed of evacuees from New Orleans (92\%). Six percent of mail survey respondents claimed to have Acadian (or "Cajun") heritage. For the subset of mail data for which we had measures of social connection (survey 2), $35 \%$ of respondents report that they were born in the parish or county in which they lived before Hurricane Katrina. We construe this as a proxy for connection to place. Sixty-five percent of the Houston sample was engaged in the labor force before Hurricane Katrina. A small proportion, 13\%, owned their own home, and the average respondent had lived in the New Orleans area (or some other part of the affected region)

\footnotetext{
${ }^{10}$ While summary statistics for race are not provided with the Houston data, most of the respondents to this survey were African Americans.
} 
for 26 years. Intentions to return across the two populations are significantly different$88 \%$ for the mail survey versus $29 \%$ for the Houston survey.

We report two sets of estimation results: the first based on the mail surveys conducted by Center for Natural Hazards Research at East Carolina University and second based on self administered questionnaires of Katrina evacuees living in Houston, TX. Table 2 reports the logistic regression estimation results for the mail data. The explanatory variables in the estimated model are jointly significant $\left(\chi^{2}=92.15\right)$. Results indicate that household income before Katrina, whether their residence was located in the New Orleans metropolitan area, whether the respondent is a senior citizen, and whether the respondent was born in the parish/county in which they lived before the storm have a statistically significant influence on the evacuee's return decision. The coefficient of household income is positive, indicating that higher income households are more likely to return to their pre-Katrina residence, but the influence diminishes with income (negative quadratic term).

Controlling for the percentage of damage in a county, residents of the New Orleans metropolitan area are less likely to return home, all else being equal. New Orleans residents are $7 \%$ less likely to return. Senior citizens are almost $5 \%$ less likely to return. The parish-born parameter estimate is negative, indicating that those respondents that were born in the parish or county in which they lived before Katrina are less likely to return. This result is counter to our expectations, as we envisioned this covariate as an indicator of social connection to place, which would lead us to expect a positive coefficient. In any event, the marginal effect is not statistically significant. Lastly, the 
economic impact dataset (survey 1) exhibited a higher likelihood of return. Unfortunately, due to missing and inconsistent data, we were not able to record wage differentials corresponding with the home and host region for the mail sample.

Table 2 also reports the estimation results for the Houston data set. Results indicate that education level, age, employment status, marital status, and home ownership influence the likelihood of return. Respondents with at least a college level education and those under the age of 30 are less likely to return. Respondents that were working before Katrina are more likely to return home, as are married respondents. Home ownership has a significant influence on the likelihood of return, increasing the probability by $21 \% .^{11}$

The Houston model also includes the wage differential. For this dataset, the real wage differential $\left(W D_{j}\right)$ for $j$ labor classification is defined as:

$$
W D_{j}=W_{j}^{\text {Host }}-\frac{C P I^{\text {Host }}}{C P I^{\text {Home }}} \cdot W_{j}^{\text {Home }},
$$

where $W_{j}^{\text {Host Home }}$ denotes an hourly mean wage in Houston and the home location (primarily New Orleans), respectively, for $j$ labor classification in May 2005, and $\mathrm{CPI}^{\text {Host Home }}$ denotes the Consumer Price Index for Houston and the home location,

\footnotetext{
${ }^{11}$ For the Houston dataset, we also estimated an ordered logit regression using the dependent variable with the values of very unlikely, somewhat unlikely, somewhat likely, and highly likely categories. The sign and significance of most coefficients are the same as the logit regression. We only report the results from the logit regression in order to compare the results with the mail survey.
} 
respectively, as of May 2005. ${ }^{12}$ The average real wage differential was $\$ 1.55$ per hour, indicating that, on average, households in the Houston sample could earn more money by staying in the Houston area. The coefficient on wage differential is negative and statistically significant. A $\$ 1$ increase in the wage differential decreases the likelihood of return by almost $6 \%$. We use equation (4) to calculate average WTP to return home. Our point estimate is $\$ 1.94$ per hour (2005 USD) with a 95\% confidence interval of \$1.79 and \$2.30 (Krinsky and Robb 1986). The dummy variable indicating the New Orleans metropolitan area captures site specific amenity affects of return migration for the majority of the sample vis-à-vis other Gulf locations. Beyond this dichotomy for the return location, our WTP measure assumes no intra-site variation in location-specific amenities (i.e., homogeneity of amenities within the Houston and home sites) and homogeneity of amenity perceptions within the population of interest. ${ }^{13}$

\section{Discussion}

Our results provide insight into the return migration decision of households that have been displaced due to natural disaster. The displacement of people can have major social, psychological, and economic implications. Researchers have examined the evacuation decision, the impact that evacuees have upon their host region, and social and psychological impacts of the disaster and displacement upon evacuees. There has been

\footnotetext{
12 The wage data come from the Department of Labor, Bureau of Labor Statistics, the Occupational Employment Statistics (OES) program. The data provided wage estimates for over 800 occupations by geographic area (http://www.bls.gov/oes/home.htm).

${ }^{13}$ Variation in amenities within sites is largely unobserved because of data limitations.
} 
much less research ${ }^{14}$ on an important aspect of recovery-which households will subsequently return and why? Our sense is that many have assumed in the past that all or most evacuees will return, but this is not necessarily so, especially for large disasters that cause mass destruction and highlight the vulnerability of a particular area. Damage from the disaster, perceptions of vulnerability of the home community, expectations of economic conditions, the behavior of family and friends, and connections to place could all influence the likelihood of return. The magnitude and composition of the returning population has implications for disaster recovery.

We postulate a simple benefit-cost structure on the return decision in order to conduct empirical analysis of two unique datasets. The first corresponds with evacuees from the Gulf region that responded to one of two mail surveys. While the mail surveys were designed for primarily other purposes (to measure evacuation behavior and expenditures in one case, and opinions of rebuilding project in the other), we are able to assess the respondent's intentions of returning to their home after evacuation. The adjusted overall response rate to these two surveys is approximately $22 \%$. We make no claim that this sample is representative of households in the Gulf region. Nonetheless, we can assess what influences the likelihood of return in order to learn something about the decision making process.

Our results suggests that household income influences the likelihood of return, though the marginal effect is rather small - a one thousand dollar increase in household

${ }^{14}$ Elliott and Pais (2006) are the only authors that we are aware of to examine the return migration decision in a quantitative framework. Falk, Hunt, and Hunt (2006) speculate on how the demographics of New Orleans might change in the wake of Hurricane Katrina. 
income increases the likelihood of return by $0.3 \%$. Residents of metropolitan New Orleans are $7 \%$ less likely to return home. The metropolitan area includes counties most heavily damaged by Katrina; however, estimates suggest that the percent of houses with damage does not significantly affect overall likelihood of return. Given the non-uniform damage distributions within a county, the county level aggregation in this covariate could be a source of inaccuracy. A particularly vulnerable group, senior citizens are less likely to return to their home (marginal effect $=5 \%$ ). This result could reflect heightened perceptions of vulnerability in this population.

We were surprised to find that individuals born in the parish or county in which they lived before Katrina were less likely to return, though the marginal effect for this variable was not statistically significant. We hypothesized that sense of place would be stronger among these individuals, and thus likelihood of return would be greater, but the data do not support this contention. Indicator variables for parents being born in the county (or a nearby county) in which the individual lived proved to have no influence on the pattern of return migration responses. Moreover, those that consider themselves "Cajun" (Acadian) are no more likely to return than other respondents. Research suggests a possible explanation for this finding - the extent of damage tends to cause more distress to people with deep roots in a particular environment (Albrecht 2006). Thus, those with deeper connections to place may be more highly traumatized leading to a lower likelihood of return.

Our results for the mail sample differ somewhat from those of Elliott and Pais (2006). They examine the return migration decision with interval-scaled data and OLS, 
finding that only household income, home ownership, and whether the respondent's home was destroyed influence the return migration decision. However, they find that income has a negative effect on the likelihood of return, as does loss of home, while home ownership has a positive effect. They find no influence of age or place of residence (New Orleans versus other Gulf Coast communities) on return migration. African Americans are no more or less likely to return in their model; we find similar results with regard to race.

Our second dataset corresponds with primarily minority Katrina evacuees in Houston, TX. Our logistic regression results suggest that education, age, employment status, marital status, and home ownership influence the likelihood of return. Respondents with at least a college level education are $7 \%$ less likely to return home than are the less educated. Those under the age of 30 are $11 \%$ less likely to return. Respondents that were working before Katrina are $9 \%$ more likely to return home than those that were not working, and married respondents are $11 \%$ more likely to return home. Similar to Elliott and Pais (2006) home ownership has a large influence on the likelihood of return, increasing the probability by $21 \%$. Household income has no effect on the likelihood of return for this sample, nor does the number of years that the respondent lived in the area prior to evacuation. The former coefficient likely reflects the low variability of income in the Houston data; the latter covariate was included as a proxy for connection to place, and again we find little support for this aspect influencing the likelihood of return. Neither of our models finds that the extent of damage in a county influence return migration, but there could be error in this variable (as noted above). 
With the Houston dataset, we examine not only the influence of household characteristics, but also individual-specific wage differentials. The economic literature on migration has long recognized that labor market conditions influence migration patterns, as do the prices of location-specific goods and the levels of spatial amenities. In a world of homogeneous agents with perfect information, with no connection to place, and in which moving was costless and could be instantaneously realized, the equilibrium levels of wages and rents should adjust to reflect the value of location-specific amenities (Roback 1982). Under these conditions utility levels of consumers and profits of firms would be equalized across space. Wages would be higher and land rents lower in areas with poor amenities, while amenity rich locations would pay lower wages and witness higher land rents.

A number of migration studies have found persistent differentials in wages across regions while controlling for amenities (Clark and Cosgrove 1991; Greenwood et al. 1991). Cultural constraints are one factor that could foster persistent wage differentials (Frey and Liaw 2005). Individual need for social support networks, kinship ties, and access to informal employment opportunities could influence migration patterns. Information flows are influenced by social networks, which could inhibit or distort knowledge of prices, wages, and amenities at other locations. Connection to place in which an individual has lived may also inhibit out-migration.

We include a number of proxies for connection to place (which for our purposes could relate to sense or identity, kinship ties, social networks, or other cultural constraints) in our regression models. We fine little influence of these factors on the 
likelihood of return. These results could reflect the unimportance of place in the return migration decision, the poor quality of our proxies, or mis-specification of the place phenomenon in our regression models. Nonetheless, we are able to make inferences about the value of returning home using individual-specific wage differentials for the Houston sample.

Real wage differentials are the differences in hourly earnings at home and host locations for a respondent's job class, controlling for home and host region price levels. The average (median) real wage differential is $\$ 1.55$ (\$0.71) per hour, ranging from $\$ 5.74$ to $\$ 12.78$. Less than $5 \%$ of the wage differentials were negative, implying that Houston offers higher real wages for the overwhelming majority of the evacuees. While we are unable to control for amenity levels across the home and host region, we do find the expected negative effect of wage differential on the likelihood of return. Since a larger wage difference implies that the individual faces higher opportunity cost of return, we interpret the wage differential as an implicit price of return. It is an estimate of the amount of hourly income that they must give up to return home.

Our willingness to pay model in (2-4) formalizes the relationship between the economic benefit of returning home and the cost implied by the wage differential. The Houston data suggest that some evacuees choose to return home despite the fact that they could earn a higher wage at their host location. In this sense, Hurricane Katrina provides a natural experiment for analyzing migration decisions. Individuals that might have never left their home are suddenly presented with the opportunity to migrate by making their evacuation decision permanent. The natural disaster provides an exogenous shock 
to the spatial pattern of labor that may allow one to assess the underlying causes of persistent wage differentials.

We employ the WTP formula in (4) to estimate the benefit of returning home. Our results suggest that the average individual is willing to sacrifice $\$ 1.94$ an hour in higher wages to return home, with a 95\% confidence interval of \$1.79 and \$2.30 (2005 USD). For an individual employed full-time, this implies an annual willingness to pay of $\$ 3,954$ (95\% confidence interval $\$ 3,651$ - $\$ 4,692)$. While connection to place as we have defined it may not be the factor motivating return migration, the data suggest that something draws individuals to return home in the face of real and significant economic cost.

\section{Conclusion}

Natural disasters can unleash widespread death and destruction, displace hundreds of thousands of people, and cause major interruptions in the everyday economic life of still greater populations. Economists have examined evacuation, recovery, and transition, but have not looked at the microeconomic decision of displaced households to return home. We explore the evacuation-migration decisions of Hurricane Katrina survivors using two unique datasets that include stated preferences on return migration. For a sample of evacuees in various locations, we find that household income increases the likelihood of returning home. This result is in line with our expectations, as households with higher income have better resources to make the return trip, are more likely to own homes in areas less likely to have been flooded, and have better resources to rebuild in the event that their home has been damaged. However, this result differs from the only 
other empirical analysis that we are aware of, which finds a negative relationship between income and likelihood of return (Elliott and Pais 2006). Senior citizens and residents of metropolitan New Orleans are less likely to return home. Percentage of damaged homes in a county does not influence the likelihood of return, but the aggregate level of this measure complicates interpretation.

Our second model deals with a dataset of evacuees in Houston, TX. The Houston evacuee data represent quite a unique population: the sample has a third of respondents with a less than high school education, is overwhelmingly African American (over 98\%), and almost half of the respondents report income less than $\$ 15,000$ per year. For this population, we find that education and youthfulness (being under 30 years of age) decrease the likelihood of return, while those that were employed before Katrina, those that are married and that own a house are more likely to return. Home ownership has the large influence on the likelihood of return, increasing the probability by $21 \%$. These sets of results are useful in their own right in that they provide insight into the nature of the return migration decision, allow one to make inferences about how the economic and cultural recovery of an area may proceed, and suggest policies that might aid in recovery.

For the Houston sample, we are also capable of exploring the relationship between wage differentials in the home and host region and the likelihood of return. We examine wage differentials in light of the literature on economic migration, in which households are assumed to sort over space according to wages, the prices of locationspecific commodities (e.g. land), and spatial amenities. The persistence of significant wage differentials after controlling for land rents and spatial amenities suggests that there 
could be some component of behavior that forestalls spatial arbitrage. Cultural constraints, such as kinship relations or connection to place (Frey and Liaw 2005), could operate to inhibit migration.

While we find no evidence that proxies for what we call "connection to place" affect the likelihood of return migration in either of our datasets, we do find that households do intend to return home in spite of real economic costs in terms of real wage differentials across the home and host location. We exploit individual variation in wage differentials to estimate the impact on the likelihood of return and find a statistically significant and negative effect - those that face higher opportunity costs of return in terms of higher relative real wages in Houston tend to stay in Houston, while those that face lower or negative opportunity costs tend to return. The fact that some individuals will accept lower wages to return provides a signal of value that one could attribute to returning home. For the sample of Houston evacuees, we estimate that the average household is willing to give up $\$ 1.94$ per hour to return home. Assuming that the earning individual works full time, this corresponds with an annual WTP of $\$ 3,954$. These numbers are limited in their applicability due to the unique characteristics of the Houston sample, but the results are encouraging and suggest that this approach should be explored further with other datasets. 


\section{References}

Albrecht, Glen. 2006. Solastalgia. Alternatives Journal 32:33-36.

Baker, E.J. 1991. Hurricane Evacuation Behavior. International Journal of Mass Emergencies and Disasters 9:287-310.

Barringer, Herbert R., Robert W. Gardner, and Michael J. Levin. 1993. Asians and Pacific Islanders in the United States: A 1980 Census Monograph Russell Sage Foundation: New York, NY.

Bean, Frank D. and Marta Tienda. 1987. The Hispanic Population of the United States: A 1980 Census Monograph Russell Sage Foundation: New York, NY.

Bowden, M., C. Pijawka, G.S. Roboff, K.J. Gelman, and D. Amaral. 1977. Reconstruction Following Disaster J.E. Haas, R.W. Kates, M.J. Bowden (Eds.) MIT Press: Cambridge, MA.

Cameron, Trudy Ann and Michelle D. James. 1987. Efficient Estimation Methods for 'Closed-Ended' Contingent Valuation Surveys. Review of Economics and Statistics 69(2):269-76.

CBS News. 1 September 2005. Mississippi Coast Areas Wiped Out. http://www.cbsnews.com/stories/2005/09/01/katrina/main810916.shtml 
Clark, David E. and James C. Cosgrove. 1991. Amenities versus Labor Market Opportunities: Choosing the Optimal Distance to Move. Journal of Regional Science 31(3):311-328.

Dow, K. and S.L. Cutter. 1997. Crying Wolf: Repeat Responses to Hurricane Evacuation Orders. Coastal Management 26:237-51.

Elliott, James R. and Jeremy Pais. 2006. Race, Class, and Hurricane Katrina: Social Differences in Human Responses to Disaster. Social Science Research 35:295321.

Falk, William W., Matthew O. Hunt, and Larry L. Hunt. 2006. Hurricane Katrina and New Orleanians' Sense of Place: Return and Reconstruction or 'Gone with the Wind'? Du Bois Review 3(1):115-28.

Farley, Reynolds and Walter R. Allen. 1987. The Color Line and the Quality of Life in America: A 1980 Census Monograph Russell Sage Foundation: New York, NY.

Federal Emergency Management Agency (FEMA). 22 August 2006a. By the Numbers One Year Later - FEMA Recovery Update for Hurricanes Katrina. www.fema.gov/news/newsrelease.fema?id=29109

Federal Emergency Management Agency (FEMA). 22 August 2006b. Hurricane Katrina, One-Year Later. www.fema.gov/news/newsrelease.fema?id=29108

Frey, William H. and Kao-Lee Liaw. 2005. Migration within the United States: Role of Race-Ethnicity. Brookings-Wharton Papers on Urban Affairs 207-62. 
Frey, William H. and Audrey Singer. 2006. Katrina and Rita Impacts on Gulf Coast Populations: First Census Findings. The Brookings Institution. Special Analysis in Metropolitan Policy.

Gieryn, Thomas. 2000. A Space for Place in Sociology. Annual Review of Sociology 26:463-96.

Gladwin, H. and W.G. Peacock. 1997. Warning and Evacuation: A Night of Hard Choices. In Hurricane Andrew: Ethnicity, Gender, and the Sociology of Disasters W.G. Peacock, B.H. Morrow, and H. Gladwin (Eds.), Routledge: London.

Graves, Phllip E. 1979. A Life-Cycle Empirical Analysis of Migration and Climate, by Race. Journal of Urban Economics 6:135-47.

Graves, Phllip E. 1980. Migration and Climate. Journal of Regional Science 20(2):22737.

Greene, W. 2003. Econometric Analysis, $5^{\text {th }}$ Ed. Upper Saddle, NJ: Prentice Hall.

Greenwood, Michael J. 1975. Research on Internal Migration in the United States: A Survey. Journal of Economic Literature 13:397-433.

Greenwood, Michael J. and Gary L. Hunt. 1989. Jobs versus Amenities in the Analysis of Metropolitan Migration. Journal of Urban Economics 25:1-16. 
Greenwood, Michael J., Gary L. Hunt, Dan S. Rickman, and George I. Treyz. 1991.

Migration, Regional Equilibrium and the Estimation of Compensating Differentials. American Economic Review 81(5):1382-1390.

Greenwood, Michael J. 1997. Internal Migration in Developed Countries. in Handbook of Population and Family Economics Mark R. Rosenzweig and Oded Stark (Eds.) Elsevier: New York, NY.

Haab, Timothy C. and Kenneth E. McConnell. 2002. Valuing Environmental and Natural Resources: The Econometrics of Non-Market Valuation Edward Elgar: Cheltenham, UK.

Kates, R.W., C.E. Colten, S. Laska, and S.P. Leatherman. 2006. Reconstruction of New Orleans after Hurricane Katrina: A Research Perspective. Proceedings of the National Academy of Sciences 103(40):14653-60.

Krinsky, I. and A.L. Robb. 1986. On Approximating the Statistical Properties of Elasticities. Review of Economics and Statistics 68(4):715-719.

National Weather Service (NWS). June 2006. Service Assessment: Hurricane Katrina August 23-31, 2005. National Weather Service. National Oceanic and Atmospheric Administration. US Department of Commerce.

Roback, Jennifer 1982. Wages, Rents, and the Quality of Life. Journal of Political Economy 90:1257-78. 
Rosen, Sherwin. 1974. Hedonic Prices and Implicit Markets: Product Differentiation in Perfect Competition. Journal of Political Economy 82(1):34-55.

Sjaastad, Larry A. 1962. The Costs and Returns of Human Migration. Journal of Political Economy 70(5), Part 2:80-93.

Tienda, Marta and Franklin D. Wilson. 1992. Migration and the Earnings of Hispanic Men. American Sociological Review 57(5):661-90.

Whitehead, John C., Bob Edwards, Marieke Van Willigen, John R. Maiolo, Kenneth Wilson, and Kevin T. Smith. 2000. Heading for Higher Ground: Factors Affecting Real and Hypothetical Hurricane Evacuation Behavior Environmental Hazards 2:133-42.

Whitehead, John C. 2005. Environmental Risk and Averting Behavior: Predictive Validity of Jointly Estimated Revealed and Stated Behavior Data. Environmental and Resource Economics 32(3):301-16.

Wilson, R.K. and R.M. Stein. 2006. Katrina evacuees in Houston: One-year out. Working Paper. Division of Social Sciences. Rice University.

U.S. Congress. Congressional Budget Office(CBO). January 2006. The Budget and Economic Outlook: Fiscal Years 2007 to 2016.

U.S. Congress. U.S. House of Representatives. Committee on Government Reform (CGR). 2006. A failure of initiative: The final report of the Select Bipartisan 
Committee to Investigate the Preparation for and Response to Hurricane Katrina.

109th Cong., 2nd sess. H. Rpt:109-377. 
Table 1. Variable Definitions and Summary Statistics

\begin{tabular}{|c|c|c|c|c|c|}
\hline \multirow{2}{*}{ Variable } & \multirow{2}{*}{ Description } & \multicolumn{2}{|c|}{ Mail Survey } & \multicolumn{2}{|c|}{ Houston Survey } \\
\hline & & Mean & Std. Dev. & Mean & Std. Dev. \\
\hline RETURN & Returning to pre-Katrina residence $(=1)$ & 0.887 & 0.316 & 0.290 & 0.454 \\
\hline INCOME & $\begin{array}{l}\text { Household annual income in thousand } \\
\text { dollars }\end{array}$ & 51.434 & 32.560 & 18.704 & 15.887 \\
\hline COLLEGE & Attended college $(=1)$ & 0.430 & 0.495 & 0.328 & 0.470 \\
\hline UNDER30 & Age under $30(=1)$ & 0.208 & 0.406 & 0.640 & 0.480 \\
\hline SENIOR & Age over $63(=1)$ & 0.256 & 0.437 & 0.008 & 0.089 \\
\hline NOMA & $\begin{array}{l}\text { Residence located within the New Orleans } \\
\text { Metropolitan area }\end{array}$ & 0.316 & 0.465 & 0.923 & 0.266 \\
\hline PERCDAM & Percent of damaged property in county & 0.449 & 0.232 & 0.452 & 0.214 \\
\hline MALE & Gender answered as male $(=1)$ & 0.540 & 0.499 & 0.508 & 0.500 \\
\hline BLACK & Race-ethnic group answered as black $(=1)$ & 0.129 & 0.335 & & \\
\hline CAJUN & Race-ethnic group answered as Cajun $(=1)$ & 0.067 & 0.250 & & \\
\hline IMPACT & $\begin{array}{l}\text { Observation from Economic Impact } \\
\text { survey (survey } 1 \text { of mail portion)* }(=1)\end{array}$ & 0.677 & 0.468 & & \\
\hline PARISH & Born in parish/county of residence* $(=1)$ & 0.348 & 0.478 & & \\
\hline WORKING & Employed before Katrina $(=1)$ & & & 0.652 & 0.477 \\
\hline MARRIED & Married $(=1)$ & & & 0.171 & 0.376 \\
\hline CHILDREN & Number of children & & & 2.015 & 1.803 \\
\hline OWNHOME & Own home residence $(=1)$ & & & 0.128 & 0.335 \\
\hline LIVEDYR & Number of years lived in New Orleans & & & 25.737 & 8.963 \\
\hline WAGEDIFF & $\begin{array}{l}\text { Real wage difference by labor class } \\
\text { (Houston wage - NOLA wage) }\end{array}$ & & & 1.553 & 2.049 \\
\hline
\end{tabular}

Notes: The summary statistics for the mail survey is based on 746 observations. The sample size for the Houston survey is 756. * IMPACT data did not record information on social/family connections to the home location; descriptive statistics for PARISH correspond with the subset of the mail data that recorded social/family connections $(n=241)$. 
Table 2. Logistic Regression Results for the Likelihood of Return

\begin{tabular}{|c|c|c|c|c|c|c|c|c|}
\hline \multirow[b]{2}{*}{ Variable } & \multicolumn{4}{|c|}{ Mail Survey } & \multicolumn{4}{|c|}{ Houston Survey } \\
\hline & Coeff. & $\begin{array}{l}\text { Std. } \\
\text { Err. }\end{array}$ & $\begin{array}{c}\text { Marg. } \\
\text { Eff }\end{array}$ & $\begin{array}{l}\text { Std. } \\
\text { Err. }\end{array}$ & Coeff. & $\begin{array}{l}\text { Std. } \\
\text { Err. }\end{array}$ & $\begin{array}{c}\text { Marg. } \\
\text { Eff }\end{array}$ & $\begin{array}{l}\text { Std. } \\
\text { Err. }\end{array}$ \\
\hline CONSTANT & 1.005 & 0.649 & & & -2.239 & 0.595 & -0.440 & 0.114 \\
\hline INCOME & $0.040 * *$ & 0.016 & $0.003 * *$ & 0.001 & 0.003 & 0.015 & 0.000 & 0.003 \\
\hline INCOME2 & $-3.0 \mathrm{e}-04 * *$ & $1.2 \mathrm{e}-04$ & $-2.0 \mathrm{e}-05^{*}:$ & $1.0 \mathrm{e}-05$ & $-7.1 \mathrm{e}-06$ & $1.9 \mathrm{e}-04$ & $-1.4 \mathrm{e}-06$ & $3.8 \mathrm{e}-05$ \\
\hline COLLEGE & 0.297 & 0.294 & 0.02 & 0.019 & $-0.397 *$ & 0.203 & $-0.075^{* *}$ & 0.037 \\
\hline UNDER30 & 0.113 & 0.351 & 0.007 & 0.022 & $-0.561 * *$ & 0.180 & $-0.114 * *$ & 0.037 \\
\hline SENIOR & $-0.607 *$ & 0.331 & $-0.047 * *$ & 0.029 & 0.329 & 0.861 & 0.069 & 0.192 \\
\hline NOMA & $-0.976^{* *}$ & 0.346 & $-0.078 * *$ & 0.032 & $1.054 * *$ & 0.400 & $0.163 * *$ & 0.045 \\
\hline PERCDAM & -0.31 & 0.738 & -0.021 & 0.05 & 0.473 & 0.402 & 0.093 & 0.079 \\
\hline MALE & 0.265 & 0.256 & 0.018 & 0.018 & -0.052 & 0.176 & -0.010 & 0.035 \\
\hline BLACK & 0.229 & 0.409 & 0.014 & 0.024 & & & & \\
\hline CAJUN & -0.134 & 0.57 & -0.009 & 0.042 & & & & \\
\hline PARISH & $-0.649 * \#$ & 0.34 & -0.055 & 0.035 & & & & \\
\hline IMPACT & $1.428 * *$ & 0.374 & $0.124 * *$ & 0.04 & & & & \\
\hline WORKING & & & & & $0.672 * *$ & 0.219 & $0.125^{* *}$ & 0.039 \\
\hline MARRIED & & & & & $0.544 * *$ & 0.222 & $0.115^{* *}$ & 0.050 \\
\hline CHILDREN & & & & & 0.037 & 0.049 & 0.007 & 0.010 \\
\hline OWNHOME & & & & & $0.962 * *$ & 0.254 & $0.214^{* *}$ & 0.061 \\
\hline LIVEDYR & & & & & 0.009 & 0.010 & 0.002 & 0.002 \\
\hline WAGEDIFF & & & & & $-0.287 * *$ & 0.059 & $-0.056^{* *}$ & 0.012 \\
\hline Obs. & 746 & & & & 756 & & & \\
\hline Pseudo-R2 & 0.176 & & & & 0.086 & & & \\
\hline Log-L & -216.458 & & & & -415.679 & & & \\
\hline
\end{tabular}

